\title{
CARMAN, María. 2006. Las Trampas de la Cultura: los intrusos y los nuevos usos del barrio de Gardel
}

\section{Larissa Brito Ribeiro}

\section{(2) OpenEdition}

1 Journals

Edição electrónica

URL: http://journals.openedition.org/aa/861

DOI: 10.4000/aa.861

ISSN: 2357-738X

Editora

Programa de Pós-Graduação em Antropologia Social (UnB)

\section{Edição impressa}

Data de publição: 1 junho 2010

Paginação: 289-292

ISSN: 0102-4302

\section{Refêrencia eletrónica}

Larissa Brito Ribeiro, «CARMAN, María. 2006. Las Trampas de la Cultura: los intrusos y los nuevos usos del barrio de Gardel», Anuário Antropológico [Online], v.35 n.1 | 2010, posto online no dia 13 outubro 2015, consultado o 28 abril 2021. URL: http://journals.openedition.org/aa/861 ; DOI: https://doi.org/ 10.4000/aa.861

Este documento foi criado de forma automática no dia 28 abril 2021.

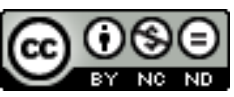

Anuário Antropológico is licensed under a Creative Commons Atribuição-Uso Não-Comercial-Proibição de realização de Obras Derivadas 4.0 International. 


\title{
CARMAN, María. 2006. Las Trampas de la Cultura: los intrusos y los nuevos usos del barrio de Gardel
}

\author{
Larissa Brito Ribeiro
}

\section{REFERÊNCIA}

CARMAN, María. 2006. Las Trampas de la Cultura: los intrusos y los nuevos usos del barrio de Gardel.Buenos Aires: Paidós.

\section{NOTA DO AUTOR}

Agradeço à Prof ${ }^{\mathfrak{a}}$ Cristina Patriota de Moura pelas suas generosas considerações à minha leitura do texto de María Carman e pelo debate teórica e metodologicamente situado desta obra, realizado no curso de Antropologia Urbana, por ela ministrado no Departamento de Antropologia da Universidade de Brasília.

A cidade e seus sujeitos nas Trampas de la Cultura

1 Num cenário de estímulo aos multiculturalismos, de tomada do patrimônio ma terial e imaterial, da memória, do meio ambiente, das produções culturais locais, como "vantagem competitiva" para as cidades, operações urbanísticas público/ privadas de requalificação e gentrification têm sido tomadas pelos governos locais como estratégia para obtenção de financiamento das cidades em face da retração da capacidade dos Estados Nacionais de regulação de suas economias.

2 O enfrentamento desta problemática pelas análises antropológicas abre um significativo desafio: como analisar as experiências de sujeitos sociais concretos da cidade em meio a tais processos econômico-financeiros globais? É no interior deste desafio que podemos localizar as investigações empreendidas por María Carman, em Las Trampas de La Cultura. Publicado pela primeira vez no ano de 2006, este trabalho é 
resultado da conjunção de um estudo etnográfico realizado pela autora entre os anos de 1993 a 2003 e de um estudo histórico dos processos subjacentes às ações de renovação urbana e requalificação cultural do Abasto, bairro situado na cidade de Buenos Aires, transformado em patrimônio cultural centrado na figura do famoso cantor de tango Carlos Gardel. Numa reconversão da área em um em preendimento chamado Cultura Abasto, Buenos Aires é inserida em um plano de transformação da cidade em "vanguarda social e cultural do país", "capital cultural da América Latina", "vitrine para o resto da nação e do mundo".

3 Em meio a esse processo, as investigações e as análises de María Carman situam-se no rastreamento das disputas em que estão inseridos os diversos atores em seus usos diferenciados do bairro para resistir, negociar ou defender sua permanência nele. Assim, a autora busca a orientação hegemônica dos discursos e das ações dos atores que tiveram maiores possibilidades de impor suas visões de mundo e seus usos do bairro como "mais legítimos", bem como a (re)construção das identidades vinculadas a estas disputas por parte daqueles que tiveram suas casas compulsoriamente desocupadas para a implantação do empreendimento.

4 As análises destas disputas transcorrem num trânsito entre a (des)construção da visibilidade e da invisibilidade dos atores envolvidos, no interior do qual o leitor percorre junto com Carman os caminhos das transformações do bairro, considerado primeiramente como Bronx Portenho (entre 1993 e 1996) para, em seguida, passar pela sua gentrification (entre 1997 e 1998). Finalizando o processo analisado pela autora, desemboca-se no culto à cultura, associado às políticas de multiculturalismo (entre 1999 e 2003), marcadas pela atração de consumidores de classe média e pela expulsão dos ocupantes das casas.

5 Ao explorar um extenso material histórico e relatos orais, a autora reconstrói o processo de formação do bairro em torno do Mercado do Abasto no final do século XIX, sob os efeitos das correntes migratórias que intensificaram a demanda por habitação em Buenos Aires, o que deu origem ao inquilinato e aos cortiços, tendo seu auge no começo do século XX. Como resultado, Carman aponta uma superposição de formas de assentamentos, resultando numa combinação entre submercado de inquilinato, autoconstrução em lote próprio nas zonas afastadas do centro urbano, formação das villas miseria e dos hotéis-pensão.

6 Seguindo o efeito das políticas habitacionais dos Governos Militares, é deflagrado o surgimento, na década de 1980, da categoria dos ocupantes, como resultado da adoção da Lei do Inquilinato e da modificação do Código de Planejamento Urbano. Tais políticas cercearam progressivamente o direito à habitação urbana aos setores populares, o que trouxe como consequência a retirada de muitas famílias das condições legais de habitação e a formação das ocupações dos imóveis, levando ao que a autora denuncia como "máxima ilegalidade" em função da progressiva ausência das políticas públicas da cidade.

7 Essas ocupações, que em dado momento eram mesmo incentivadas pelo poder público local, compõem uma lógica que revela a problemática habitacional e seus enfrentamentos por parte deste. Num jogo de classificações associado à constituição da ilegalidade urbana, Carman revela a construção da legitimidade cultural através do patrimônio cultural, atribuída a determinados atores, atrelada ao atendimento das demandas de setores econômicos interessados no Abasto. No interior desse movimento de legitimação de determinados grupos, ilegalização de outros, visibilidade e 
invisibilidade, a autora desvenda as múltiplas e complexas práticas de resistência dos ocupantes para se afastarem de uma classificação estigmatizante, mobilizada para deslegitimar a sua permanência no bairro.

8 Para tanto, Carman adentra a vida cotidiana dos ocupantes "ilegais" das casas e dos baldios no período anterior à revitalização do bairro (entre 1993 e 1996), desvendando a particularidade de seus interlocutores sob a invisibilidade e a identidade atribuída de ocupantes "ilegais". Revela-se então quem eles são, suas origens, formas de trabalho, organização da vida cotidiana, práticas de permanência no bairro, as tensões das redes de solidariedade constituídas e o constante jogo em face dos muitos outros com que se defrontam na sua luta pela permanência no bairro.

$\mathrm{Na}$ complexa trama de disputas já existentes entre os diferentes atores em torno das ocupações - e reatualizada pela entrada em cena do empreendimento privado - o leitor pode acompanhar a análise de Carman da (re)construção de identidades dos ocupantes, estreitamente associada a escalas de processos globais, bem como a contextos históricos específicos. No interior dessa trama, a autora desvela a "política de lugares" e a "política da memória", implementadas na cidade pela parceria público-privada em prol da revitalização da área e que resultaram em megaobras encabeçadas pelo financista húngaro George Soros.

10 Caracterizados pela destruição do patrimônio local reivindicado pelos ocupantes das casas e por aqueles que compunham a movimentação cultural popular que marcava o Abasto como "epicentro cultural", "lugar mais portenho de Buenos Aires", muito antes de Carlos Gardel, esses empreendimentos mercantilizaram os espaços do bairro, desalojaram os seus ocupantes, demolindo suas casas e dando-lhes novos significados.Tratou-se, então, de uma recodificação da tradição que elegeu um ícone específico, Gardel, como elemento que epitomiza a memória do bairro em detrimento de suas demais memórias, conformando uma biografia oficial do Abasto. Carman, no entanto, aponta esse processo como não-inédito, semelhante às políticas de transformação de outras cidades do mundo em "cidades globais", mas que toma matizes particulares pelo modo como seus interlocutores nele se inserem. As intenções explícitas do projeto Cultura Abasto são, então, reveladas pela autora como condicionadas às estratégias do empreendimento de saída "negociada" da cara menos turística do bairro, menos ligada à figura de Gardel, imprimindo uma nova ordem moral à cultura. Para tanto, Carman nos põe diante do que representava a permanência de ocupantes que ainda restavam quando da inauguração do Shopping Abasto de Buenos Aires e que reivindicavam serem os legítimos herdeiros da história do bairro: uma "fissura na eficácia simbólica" (:180) do empreendimento, fechada através da expulsão desses ocupantes.

11 Para além do âmbito local, a autora indica o caráter paradigmático do evento político de inauguração do shopping, transformado em elemento de "recuperação nacional do bairro", alçando-o a ícone da identidade nacional por um efeito de inovação conservadora de um único elemento tradicional. Um culto à la cultura estabelece-se paradoxalmente por meio da revalorização de um aspecto único, singular e especial do lugar, mas que só pode ser compreendido através do que Carman aponta como uma lógica que pretende "instaurar uma relação entre ideologia e lugar", imprimindo um "sentido de lugar". Desta forma, sob a promoção da cultura para eleger a cidade à categoria de "cidade global", Carman desvenda um jogo de inclusão e exclusão de 
determinados segmentos sociais, denunciando o privilegiamento dos investimentos em cultura como mobilizadores dos investimentos em políticas urbanas e sociais.

Nessa conjunção de análises, a autora prepara um fértil terreno e fornece novos elementos para que se reflita sobre a cidadania no âmbito das novas estratégias das políticas urbanas. É no drama das (re)construções e das (re)negociações de identidades vivenciado pelos ocupantes das casas tomadas no Abasto que Carman nos desvela a complexidade do jogo de forças em que estão inseridos esses atores, para analisar o alcance de seu poder face aos demais atores em suas práticas de cidadania. Suas análises são, portanto, inspiradoras para aqueles que pretendem enveredar na análise desses jogos contemporaneamente frequentes em diversas cidades do mun do sob o epíteto do desenvolvimento, do meio ambiente, da sustentabilidade, da cultura, como estratégias de resolução dos problemas da cidade e de seus sujeitos, ofuscados por modelos urbanos idealizados.

\section{NOTAS}

1. Este termo foi utilizado por Henri Acselrad ("Sentidos da Sustentabilidade Urbana". In: (org.) 2001. A duração das cidades: sustentabilidade e risco nas políticas urbanas. Rio de Janeiro: DP\&A. pp. 105-137) para se referir às estratégias contemporâneas dos governos municipais para atraírem recursos e investimentos financeiros para as cidades brasileiras.

\section{AUTORES}

\section{LARISSA BRITO RIBEIRO}

Departamento de Antropologia/UNB 